\title{
Processing Mineralogy Study on Lead and Zinc Oxide Ore in Sichuan
}

\author{
Mei Yang ${ }^{1}$, Wending Xiao ${ }^{2}$, Xiang Yang ${ }^{1}$ and Patrick Zhang ${ }^{3, *}$ \\ 1 School of Materials Science and Chemistry Engineering, China University of Geosciences, Wuhan 430074, \\ China; yangmei@cug.edu.cn (M.Y.); yangying@cug.edu.cn (X.Y.) \\ 2 Department of Minerals Processing, Wuhan Institute of Technology, Wuhan 430073, China; \\ wendingx@hotmail.com \\ 3 Florida Industrial and Phosphate Research Institute, Florida Polytechnic University, Bartow, FL 33830, USA \\ * Correspondence: jzhang@flpoly.org; Tel.: +1-863-333-0807; Fax: +1-863-534-7165 \\ Academic Editor: Corby G. Anderson \\ Received: 16 February 2016; Accepted: 9 April 2016; Published: 22 April 2016
}

\begin{abstract}
The processing mineralogy characteristics of an oxidized lead-zinc ore from Sichuan were studied systematically using numerous modern instruments. Results showed that lead and zinc oxide content in the ore exceeded the minimum industrial grade, and also included a relatively high concentration of silver and iron. This ore is composed of many different minerals. Major zinc-containing minerals include sphalerite, hemimorphite, smithsonite, hydrozincite, zinc-containing baileychlore, and zinc-containing dolomite and calcite. Lead-containing minerals are primarily galena and cerussite with small amounts of dechenite, cesaronite, anglesite, limonite and coronadite. Gangue minerals include dolomite and calcite. Dissemination size for the main minerals ranges from medium $(0.04 \mathrm{~mm})$ to fine $(0.02 \mathrm{~mm})$. All the valuable minerals are well liberated, including galena, sphalerite, cerussite, calamine, and smithsonite. However, the dissemination relationships are complex. Lead is concentrated mainly in galena and cerussite, while zinc occurs primarily in sphalerite, calamine, and smithsonite. The theoretical recovery for lead and zinc were estimated at $72 \%$ and $67 \%$, respectively.
\end{abstract}

Keywords: oxidized lead-zinc ore; processing mineralogy; minerals compositions; dissemination characteristics; mode of occurrence

\section{Introduction}

Due to the extensive exploitation of lead-zinc deposits, lead and zinc sulfide ores are being depleted rapidly, and attention has been turned to the exploration of non-sulfide lead and zinc ores. China has abundant non-sulfide lead and zinc ores distributed mainly in Yunnan, Sichuan, Guizhou, Qinhai, Guangxi and Hunan provinces. Utilization of these resources is of significant economic importance. Because of the difficulty in separating lead from zinc ore minerals in this type of ore, it is essential to develop new technologies and processes for the utilization of this type of resource [1,2]. Process mineralogy studies of the characteristics of minerals and their changes during minerals processing operations can provide useful guidance for interpreting mineral beneficiation mechanisms, designing beneficiation flowsheets and, optimizing unit operations [3-15]. This is accomplished by measuring chemical compositions, mineral components, and mineral dissemination characteristics, and the occurrence of both the metals of interest and gangue materials. The most up-to-date and comprehensive review of non-sulfide zinc deposits was written by Borg [16]. Under this study, detailed process mineralogy was conducted on a non-sulfide lead-zinc ore from the province of Sichuan, thus providing basic data and a theoretical foundation for developing techniques to utilize this resource. 


\section{Materials and Methods}

Table 1 shows the chemical compositions of the raw ore, indicating that both lead and zinc exceed the minimum industrial grade for lead-zinc oxide ores. This ore also contains appreciable amounts of silver and iron.

Table 1. Chemical analysis of the raw ore (wt. \% unless noted otherwise).

\begin{tabular}{cccccccccccc}
\hline \multicolumn{10}{c}{ Chemical Compositions (wt. \% Unless Noted Otherwise) } \\
\hline $\mathrm{Pb}$ & $\mathrm{Zn}$ & $\mathrm{Ag}(\mathrm{g} / \mathrm{t})$ & $\mathrm{Total} \mathrm{Fe}$ & $\mathrm{S}$ & $\mathrm{MgO}$ & $\mathrm{CaO}$ & $\mathrm{Al}_{2} \mathrm{O}_{3}$ & $\mathrm{SiO}_{2}$ & $\mathrm{~K}_{2} \mathrm{O}$ & $\mathrm{Na}_{2} \mathrm{O}$ & $\mathrm{C}$ \\
4.68 & 11.47 & 47.6 & 20.86 & 2.36 & 2.30 & 17.78 & 1.14 & 4.37 & 0.093 & 0.017 & 4.49 \\
\hline
\end{tabular}

Phase analysis was conducted on the raw ore using the chemical method with the results shown in Table 2. Phase compositions are complex for both the lead and zinc minerals. Oxide minerals are dominant, followed by sulfide minerals, and iron and manganese oxides or hydroxides.

Table 2. Phase composition of the raw ore (\%).

\begin{tabular}{ccc}
\hline Phase & $\mathbf{P b}$ & $\mathbf{Z n}$ \\
\hline Oxide phase & 49.79 & 66.18 \\
Sulfide phase & 26.28 & 13.60 \\
Iron and manganese oxides or hydroxides & 23.93 & 20.22 \\
\hline
\end{tabular}

Quantitative mineral compositions of the ore were determined using a microscope and a Mineral Liberation Analyzer (MLA, FEI, Hillsboro, OR, USA), an automatic minerals measurement system, shown in Table 3.

Table 3. Mineral compositions of the raw ore (wt. \%).

\begin{tabular}{cc}
\hline Mineral & Content (wt. \%) \\
\hline Sphalerite & 2.335 \\
Hemimorphite & 5.023 \\
Smithsonite & 6.313 \\
Hydrozincite & 0.337 \\
Sheridanite & 2.325 \\
Dolomitic sphalerite & 12.639 \\
Zinc-bearing dolomite & 9.090 \\
Zinc-bearing calcite & 8.695 \\
Galena & 1.411 \\
Cerussite & 2.823 \\
Anglesite & 0.089 \\
Cesarolite & 2.826 \\
limonite & 40.045 \\
Pyrite & 2.532 \\
Others & 3.517 \\
\hline
\end{tabular}

\section{Results and Discussion}

Results show that zinc-containing minerals include sphalerite, hemimorphite, smithsonite, hydrozincite, sheridanite and zinc-bearing dolomite and calcite. Lead-containing minerals include galena, cerussite, and small amounts of anglesite and cesarolite. There are also other minerals, such as limonite (which also contains lead and zinc), acanthite, native silver, pyrite, small amounts of chalcopyrite and enargite, quartz, chlorite, mica, feldspar, and essonite. 


\subsection{Dissemination Size and Degree of Liberation of Major Minerals}

Figure 1 shows dissemination size distributions of the major minerals in the raw ore based on microscopic analysis. The dissemination size for the major minerals in this ore falls within medium range. Galena has the coarsest dissemination size, ranging from 0.16 to $2.56 \mathrm{~mm}$. The dissemination sizes for sphalerite and cerussite are also relatively coarse, ranging from 0.04 to $1.28 \mathrm{~mm}$. Hemimorphite and smithsonite have the finest size, falling between 0.02 and $1.28 \mathrm{~mm}$.

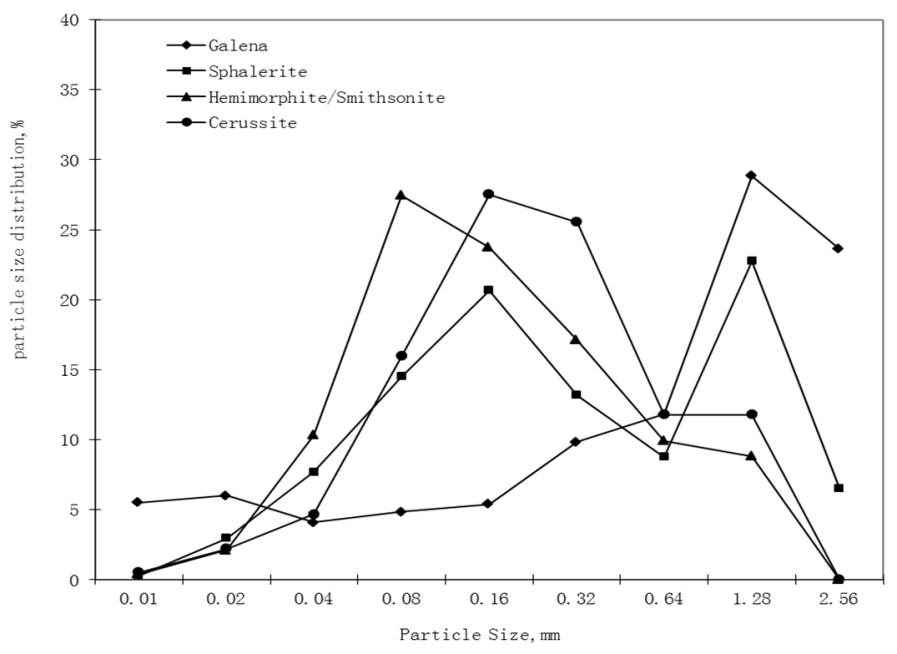

Figure 1. Dissemination size range of major minerals.

To prevent over-grinding, the degree of liberation of the minerals was measured at different grinding fineness. Results in Table 4 show that galena, sphalerite, cerussite, hemimorphite and smithsonite are all well liberated when ground to $66 \%$ passing $0.074 \mathrm{~mm}$.

Table 4. Degree of liberation of the major minerals.

\begin{tabular}{ccccccc}
\hline \multirow{2}{*}{$\begin{array}{l}\text { Grinding } \\
\text { Fineness }\end{array}$} & \multirow{2}{*}{$\begin{array}{c}\text { Size } \\
\text { Range/mm }\end{array}$} & \multirow{2}{*}{ wt. $\%$} & \multicolumn{4}{c}{ Degree of Liberation/\% } \\
\cline { 5 - 6 } & & & Galena & Sphalerite & Cerussite & Hemimorphite/Amithsonite \\
\hline \multirow{2}{*}{ 66\% passing } & $-0.1+0.074$ & 33.92 & 93.32 & 86.21 & 87.25 & 91.18 \\
$0.074 \mathrm{~mm}$ & $-0.074+0.043$ & 16.92 & 95.14 & 87.27 & 92.74 & 94.11 \\
& -0.043 & 49.16 & 97.56 & 91.33 & 95.28 & 97.1 \\
\hline \multirow{2}{*}{$87 \%$ passing } & $-0.1+0.074$ & 12.81 & 94.47 & 90.25 & 91.27 & 92.99 \\
0.074 mm & $-0.074+0.043$ & 21.62 & 96.64 & 93.57 & 96.77 & 95.62 \\
& -0.043 & 65.57 & 98.16 & 96.34 & 99.36 & 97.59 \\
\hline \multirow{2}{*}{$95 \%$ passing } & $-0.1+0.074$ & 5.49 & 97.35 & 94.40 & 94.83 & 98.46 \\
$0.074 \mathrm{~mm}$ & $-0.074+0.043$ & 19.75 & 99.61 & 96.77 & 98.81 & 99.48 \\
\hline
\end{tabular}

\subsection{Dissemination Characteristics of Major Minerals}

Dissemination characteristics of the major minerals were determined using an optical microscope, a scanning electron microscope and an energy spectrum, and they are summarized below.

\subsubsection{Sphalerite, $\mathrm{ZnS}$}

It contains $64.48 \% \mathrm{Zn}$ on average and $0.73 \%-2.38 \% \mathrm{Fe}$. As is shown in Figure 2, this is a lightly colored, iron-containing sphalerite. Some particles contain $0.3 \%-0.72 \% \mathrm{Cd}$, with a small number of particles containing indium. This ore contains two types of sphalerite formed at different periods. One type has a relatively complete crystal formation and contains relatively higher iron. The crystals 
are formed alternately with pyrite, showing idiomorphic and hypidiomorphic idiomorphic crystal aggregates, with some residual pyrite replacement as well as replacement by hemimorphite and smithsonite. In the second type, sphalerite is formed by crystalizing from colloidal solution, showing colloidal solution micro-crystal aggregates, and contains fine galena and calcite.

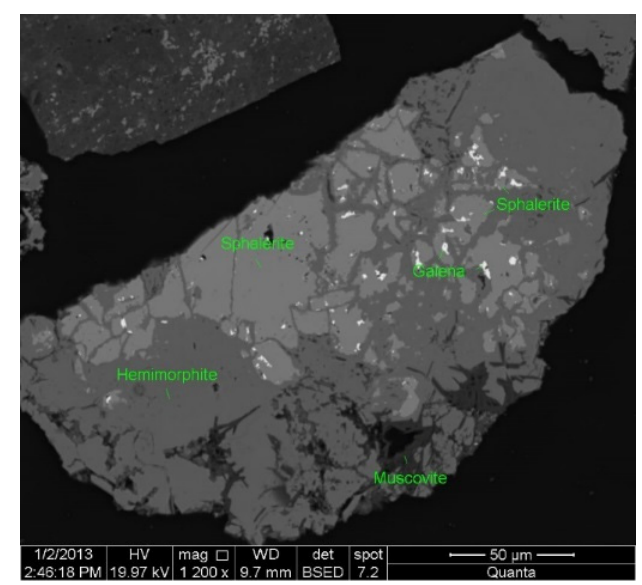

Figure 2. SEM photo showing sphalerite replaced by hemimorphite.

\subsubsection{Smithsonite, $\mathrm{ZnCO}_{3}$}

This mineral contains $43.96 \%-52.76 \%$ zinc averaging $50.93 \%$, with small amounts of $\mathrm{Ca}, \mathrm{Fe}, \mathrm{Pb}$, and $\mathrm{Si}$. The dissemination of smithsonite is complex in the following ways: (1) replacing sphalerite to form hexagonal prism crystal smithsonite aggregates; (2) crystallization of smithsonite from colloidal solution forming a bean-shaped aggregate (Figure 3); (3) local co-existence with hydrozincite, where crystal smithsonite shows a skeleton shape with densely compacted hydrozincite filling the lattices, or smithsonite is replaced by hydrozincite, forming a complex co-existence relationship; and (4) distribution in zinc-bearing dolomite by dissemination.

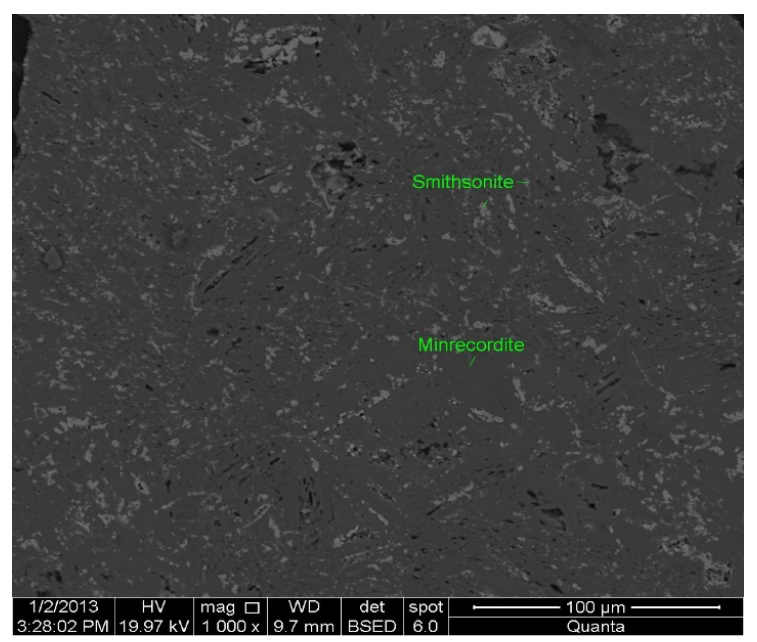

Figure 3. SEM figure showing ultrafine smithsonite particles disseminated in zinc-bearing dolomite.

\subsubsection{Hemimorphite, $\mathrm{Zn}_{4}\left(\mathrm{H}_{2} \mathrm{O}\right)\left(\mathrm{Si}_{2} \mathrm{O}_{7}\right)(\mathrm{OH})_{2}$}

This mineral is composed of $52.02 \%-54.89 \%$ zinc (averaging $53.46 \%$ ), $0.17 \%-3.90 \% \mathrm{Fe}$, and $0.17 \%-0.94 \% \mathrm{Al}$. The dissemination of hemimorphite is also complex, and takes the following forms: (1) irregular particles and plate crystals distributed in zinc-bearing dolomite (Figure 4); (2) in the 
form of common lumpy and crusty aggregates, within which there are cyclic structured metacolloid inclusions of limonite, cesarolite and calcite, and occasionally helical shape acanthite; (3) after leaching dissolution, hemimorphite fills the voids of the skeleton formed by limonite; and (4) vein pattern hemimorphite penetrates within hydrozincite, sheridanite and calcite.

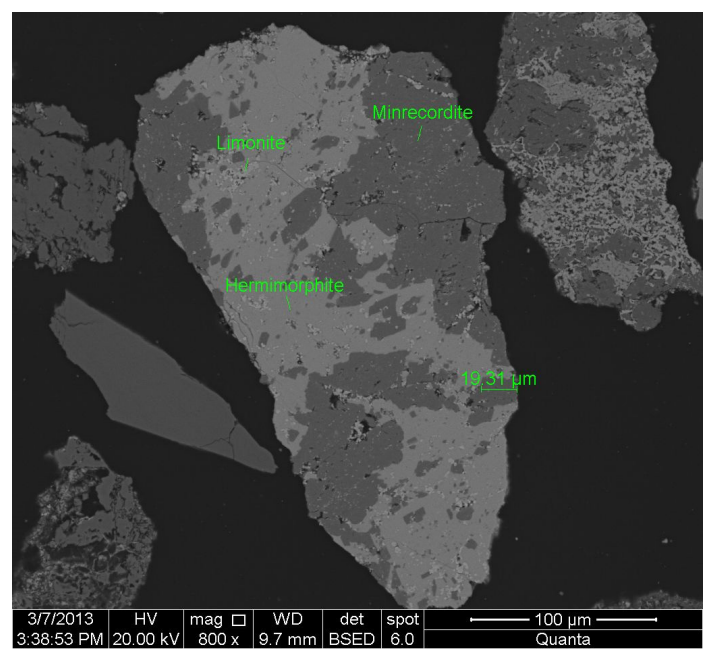

Figure 4. SEM figure showing dissemination of hemimorphite within zinc-containing dolomite.

\subsubsection{Galena, $\mathrm{PbS}$}

The galena mineral in this ore contains $86.53 \% \mathrm{PbS}$, very close to its theoretical content of $86.60 \%$, and insignificant amounts of Fe and $\mathrm{Zn}$. Two mineral formations were identified for this mineral. In the first formation, galena metasomatizes along rock cracks, forming irregular granules and lumps. The second formation involves galena co-existing with metacolloid sphalerite, with galena cemented either inside the sphalerite or along its edges. In addition, galena is often metasomatized by acanthite. Galena residual crystals can be found in acanthite. Cerussite and acanthite are also found to metasomatize with galena simultaneously.

\subsubsection{Cerussite, $\mathrm{PbCO}_{3}$}

This mineral contains $76.51 \% \mathrm{~Pb}, 0.48 \%$ zinc, $0.16 \% \mathrm{Ca}, 0.32 \% \mathrm{Fe}$, and $0.02 \% \mathrm{Si}$. Cerussite disseminates in the following modes: (1) replacing galena and often co-existing with anglesite (Figure 5); (2) self-forming cerussite crystal disseminated in smithsonite aggregates and hemimorphite crystals; (3) a small amount of cerussite is detected in limonite crystals; and (4) some micro-vein pattern cerussite is found in sphalerite cracks.

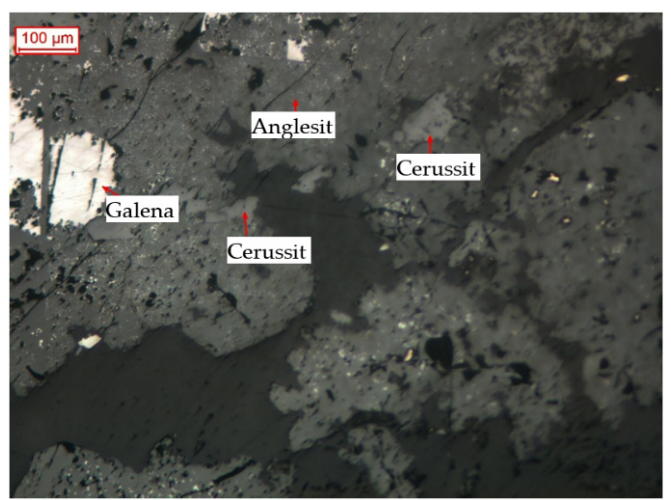

Figure 5. Reflection microscope figure showing anglesite and cerussite metasomatizing with galena. 


\subsection{Distribution of Lead and Zinc in Minerals}

\subsubsection{Distribution of Lead in Minerals}

Distributions of lead in major minerals are calculated based on quantitative minerals analysis and chemical compositions. The results are shown in Table 5. Lead is concentrated in galena and cerussite, accounting for about $72 \%$, with the rest being in cesarolite $(11.74 \%)$, limonite $(12.42 \%)$, anglesite $(1.3 \%)$, and others $(2.25 \%)$. Therefore, the theoretical lead recovery is $72 \%$, because only the lead in galena and cerussite is recoverable.

Table 5. Lead distribution in different minerals.

\begin{tabular}{cccc}
\hline Mineral & Mineral Content/\% & $\mathbf{P b}$ in Mineral/\% & Pb Distribution/\% \\
\hline Galena & 1.411 & 86.53 & 26.11 \\
Cerussite & 2.823 & 76.51 & 46.18 \\
Anglesite & 0.089 & 68.3 & 1.30 \\
Cesarolite & 2.826 & 19.43 & 11.74 \\
Limonite & 40.045 & 1.45 & 12.42 \\
Others & 52.806 & - & 2.25 \\
Total & 100.00 & - & 100.00 \\
\hline
\end{tabular}

\subsubsection{Zinc Distribution in Major Minerals}

Zinc distribution in different minerals is calculated in the same manner as lead, with the results shown in Table 6. Zinc is distributed in more minerals. Zinc in sphalerite, hemimorphite and smithsonite accounts for $66.6 \%$ of the total zinc, which also represents the theoretical recovery for zinc from this ore.

Table 6. Zinc distribution in different minerals.

\begin{tabular}{cccc}
\hline Mineral & Mineral Content/\% & Zn in Mineral/\% & Zn Distribution/\% \\
\hline Sphalerite & 2.335 & 64.48 & 13.54 \\
Hemimorphite & 5.023 & 53.46 & 24.15 \\
Smithsonite & 6.313 & 50.93 & 28.91 \\
Hydrozincite & 0.337 & 70.88 & 2.15 \\
Sheridanite & 2.325 & 22.49 & 4.70 \\
Limonite & 40.045 & 4.09 & 14.73 \\
Zinc dolomite & 12.639 & 7.66 & 8.71 \\
Others & 30.983 & - & 3.11 \\
Total & 100.00 & - & 100.00 \\
\hline
\end{tabular}

\section{Conclusions}

Both lead and zinc levels in this ore exceed the minimum industrial grade for lead-zinc oxide ores with relatively high amounts of silver and iron. Numerous minerals exist in this ore, including sphalerite, hemimorphite, smithsonite, hydrozincite, sheridanite, zinc-bearing dolomite and calcite, galena, cerussite, and small amounts of lead-vanadium manganese ore and cesarolite, limonite (which also contains lead and zinc), acanthite, natural silver, pyrite, as well as small amounts of chalcopyrite, enargite, quartz, chlorite, mica, feldspar, and essonite.

The dissemination size of the major minerals falls within the medium range. The degree of liberation is quite good for all the major valuable minerals galena, sphalerite, cerussite, hemimorphite, and smithsonite. This, to some extent, favors separation using routine beneficiation techniques. However, only about $70 \%$ of lead and zinc is found in the major minerals, with the remaining $30 \%$ disseminated in complex mineral. This means that physical separation alone could not achieve high recovery of lead and zinc from this ore. 
Lead is concentrated in galena and cerussite, while zinc is mainly found in sphalerite, hemimorphite and smithsonite, with corresponding theoretical recoveries of $72 \%$ and $67 \%$.

Author Contributions: Mei Yang directed the study and designed most of the experiments. Both Wending Xiao and Xiang Yang participated in experiments design, data analysis, and drafting the paper. Patrick Zhang served as an advisor to this research, and helped with paper design and English proof reading.

Conflicts of Interest: The authors declare no conflict of interest.

\section{References}

1. He, X.J.; Xu, X.P.; Fu, G.Q. Flotation Study of a refractory lead-zinc oxide ore from Yunnan (in Chinese). Non-ferr. Met. (Benef.) 2010, 6, 16-19.

2. He, S.M.; Wang, J.K.; Yan, J.F. Investigation on high pressure leaching of Lead-Zinc oxide ores. Hydrometallurgy 2010, 29, 159-161.

3. Zou, L.G. Process Mineralogy; Metallurgical Industry Press: Beijing, China, 2009.

4. Liang, D.Y.; Li, B.; Hong, Q.Y. Process Mineralogy Study of a low-grade, multi-metal tungsten ore from southwest China. China Tungsten Ind. 2011, 26, 20-23.

5. Caproni, G.; Ciccu, R.; Ghiani, M.; Trudi, I. The Processing of oxidised lead and zinc ores in the Campo Pisano and San Giovanni plants (Sardinia). In Proceedings of the 13th International Mineral Processing Congress, Warsaw, Poland, 4-9 June 1979; pp. 69-91.

6. Brough, C.P.; Pittuck, M.; Stenhouse, P.; Jones, O.; Rowell, R. The process mineralogy of gold at the Tuzon deposit, Liberia. In Proceedings of the Process Mineralogy '14, Cape Town, South Africa, 17-19 November 2014.

7. Hamilton, C.; Martin, C.; Zhou, J. Ore characterization and the value of Qemscan. In Proceedings of the Cu2007 Volume II Mineral Processing, Toronto, ON, Canada, 25-30 August 2007; pp. 137-145.

8. Lamberg, P. A way forward in process mineralogy-Using automated mineralogy for modeling and simulating beneficiation processes. In Proceedings of the Process Mineralogy '14, Cape Town, South Africa, 17-19 November 2014.

9. Pangum, L.S.; Glatthaar, J.W.; Manlapig, E.V. Process Mineralogy of Fluorosilicate Minerals in OK-Tedi Ores. Miner. Eng. 2001, 14, 1619-1628. [CrossRef]

10. Tungpalan, K.; Wightman, E.; Manlapig, E. Relating mineralogical and textural characteristics to flotation behavior. In Proceedings of the Process Mineralogy ‘14, Cape Town, South Africa, 17-19 November 2014.

11. De Wet, J.R.; Singleton, J.D. Development of a viable process for the, recovery of zinc from oxide ores. J. South. Afr. Inst. Min. Metall. 2008, 108, 253-259.

12. Boni, M. The Geology and Mineralogy of Non-Sulfide Zinc Ore Deposits. In Proceedings of Lead \& Zinc '05, Kyoto, Japan, 17-19 October 2005; pp. 1299-1314.

13. Petruk, W. General principles of applied mineralogy. In Applied Mineralogy in the Mining Industry; Elsevier: Amsterdam, The Netherlands, 2000; Chapter 1; pp. 1-26.

14. Zhou, J. Process Mineralogy and Applications in Process Design and Optimization. In Proceedings of Metallurgical Plant Design and Operating Strategies, Perth, Australia, 18-19 September 2006; pp. 259-260.

15. Zhou, J.; Gu, Y.; Zhou, H.Y. Process Mineralogy and Applications in Mineral Processing. In Proceedings of the XXVII International Mineral Processing Congress, Santiago, Chile, 20-24 October 2014.

16. Borg, G. A Review of Supergene Nonsulphide Zinc (SNSZ) Deposits-the 2014 Update. In Current Perspectives of Zinc Deposits; Archibald, S.M., Piercey, S.J., Eds.; Irish Association for Economic Geology: Dublin, UK, 2015; pp. 123-147.

(C) 2016 by the authors; licensee MDPI, Basel, Switzerland. This article is an open access article distributed under the terms and conditions of the Creative Commons Attribution (CC-BY) license (http://creativecommons.org/licenses/by/4.0/). 